\title{
Curcumin and Novel Synthetic Analogs in Cell-Based Studies of Alzheimer's Disease
}

\begin{abstract}
Stella Gagliardi', Valentina Franco ${ }^{1,2}$, Stefano Sorrentino', Susanna Zucca', Cecilia Pandini ${ }^{1,3}$, Paola Rota ${ }^{4,5}$, Stefano Bernuzzi ${ }^{6}$, Alfredo Costa ${ }^{7,8}$, Elena Sinforiani ${ }^{9}$, Orietta Pansarasa ${ }^{1}$, John R. Cashman ${ }^{10}$ and Cristina Cereda ${ }^{1}$
\end{abstract}

OPEN ACCESS

Edited by:

Asma Amleh,

American University in Cairo, Egypt

Reviewed by:

Abdu Adem,

United Arab Emirates University,

United Arab Emirates

Ahmed Abdellatif,

American University in Cairo, Egypt

*Correspondence:

Stella Gagliardi

stella.gagliardi@mondino.it orcid.org/0000-0002-6589-6907

Specialty section: This article was submitted to

Ethnopharmacology,

a section of the journal

Frontiers in Pharmacology

Received: 10 September 2018 Accepted: 15 November 2018

Published: 03 December 2018

Citation:

Gagliardi S, Franco V Sorrentino S, Zucca S, Pandini C,

Rota P, Bernuzzi S, Costa A,

Sinforiani E, Pansarasa $O$,

Cashman JR and Cereda C (2018)

Curcumin and Novel Synthetic

Analogs in Cell-Based Studies

of Alzheimer's Disease.

Front. Pharmacol. 9:1404.

doi: 10.3389/fphar.2018.01404

\begin{abstract}
${ }^{1}$ Genomic and Post-Genomic Center, IRCCS Mondino Foundation, Pavia, Italy, ${ }^{2}$ Clinical and Experimental Pharmacology Unit, Department of Internal Medicine and Therapeutics, University of Pavia, Pavia, Italy, ${ }^{3}$ Department of Biology and Biotechnology "L. Spallanzani", University of Pavia, Pavia, Italy, ${ }^{4}$ Laboratory of Stem Cells for Tissue Engineering, IRCCS Policlinico San Donato, Milan, Italy, ${ }^{5}$ Department of Biomedical, Surgical and Dental Sciences, University of Milan, Milan, Italy, ${ }^{6}$ Immunohematological and Transfusional Service, Centre of Transplantation Immunology, Fondazione IRCCS Policlinico San Matteo, Pavia, Italy, ' Department of Brain and Behavioral Sciences, University of Pavia, Pavia, Italy, ${ }^{8}$ Neurology Department, IRCCS Mondino Foundation, Pavia, Italy, ${ }^{9}$ Laboratory of Neuropsychology/UVA, IRCCS Mondino Foundation, Pavia, Italy, ${ }^{10}$ Laboratory of Chemistry, Human BioMolecular Research Institute, San Diego, CA, United States
\end{abstract}

Alzheimer's disease (AD) is a chronic neurodegenerative disorder that is associated with the most common type of dementia and is characterized by the presence of deposits of the protein fragment amyloid beta $(A \beta)$ in the brain. The natural product mixture of curcuminoids that improves certain defects in innate immune cells of $A D$ patients may selectively enhance $A \beta$ phagocytosis by alteration of gene transcription. In this work, we evaluated the protective effects of curcuminoids in cells from AD patients by investigating the effect on NF-KB and BACE1 signaling pathways. These results were compared to the gene expression profile of the clearance of $A \beta$. The minor curcumin constituent, bisdemethoxycurcumin (BDC) showed the most potent protective action to decrease levels of $N F-\kappa B$ and $B A C E 1$, decrease the inflammatory cascade and diminish $A \beta$ aggregates in cells from AD patients. Moreover, mannosyl-glycoprotein 4-beta-Nacetylglucosaminyltransferase (MGAT3) and vitamin D receptor (VDR) gene mRNAs were up-regulated in peripheral blood mononuclear cells from $A D$ patients treated with BDC. BDC treatment impacts both gene expression including Mannosyl (Beta-1,4-)Glycoprotein Beta-1,4-N-Acetylglucosaminyltransferase, Vitamin D and Toll like receptor mRNA and AB phagocytosis. The observation of down-regulation of BACE1 and NF-kB following administration of BDC to cells from AD patients as a model system may have utility in the treatment of asymptomatic AD patients.

Keywords: Alzheimer's disease, curcumins, next generation sequencing, NF-kB, amyloid beta, mannosylglycoprotein 4-beta- $\mathrm{N}$-acetylglucosaminyltransferase

\section{INTRODUCTION}

Alzheimer's disease $(\mathrm{AD})$ is a chronic neurodegenerative disorder that represents the most common type of dementia. $\mathrm{AD}$ is characterized by the presence of deposits of the protein fragment amyloid beta $(A \beta)$ and twisted fibers of the protein tau (tangles) in the brain (McKhann et al., 1984; Selkoe, 2001; Blennow et al., 2006). The disproportionate accumulation and aberrant aggregation of $\mathrm{A} \beta$ is associated with the onset of neurodegenerative processes. 
Medications available to treat $\mathrm{AD}$ address symptomatic issues and target glutamatergic and cholinergic neurotransmissions and often show only modest clinical benefits (Kumar et al., 2015). Recent achievements in clinical trials of novel diseasemodifying drugs such as aducanumab, show that targeting $A \beta$ clearance represents a promising strategy in prevention and treatment of AD (Panza et al., 2016). Aducanumab decreased A $\beta$ accumulation and slows cognitive decline in subjects during early stages of $\mathrm{AD}$ or in mild cognitive impairment patients (Panza et al., 2016). In addition to drugs, the study of naturally occurring compounds may offer promise for a novel therapeutic approach to treat $\mathrm{AD}$.

Curcumin [i.e., 1,7-bis(4-hydroxy-3-methoxyphenyl)1,6-heptadiene-3,5-dione, Compound 3] is a polyphenolic compound derived from the dried rhizome of the plant Curcuma Longa (Anderson et al., 2000). In animal studies, curcumin has been shown to possess neuroprotection biological properties due to its anti-inflammatory and anti-oxidant effects (Aggarwal and Harikumar, 2009; Cashman et al., 2012). Curcumin was reported to promote in vivo disaggregation of existing $A \beta$ deposits and avoid new aberrant $A \beta$ aggregation into fibrils (Zhang et al., 2006). However, clinical utility of curcumin has been limited because of its poor systemic bioavailability and chemical instability. Ahmed et al. (2010) described the effects of intraperitoneally injected curcuminoid mixtures [curcumin, bisdemethoxycurcumin (BDC) and demethoxycurcumin] and individual components on memory enhancement in an amyloid-infused rat model. The study found that, compared to curcumin, BDC (Compound 1) and demethoxycurcumin exerted a more efficacious effect on memory enhancement.

It may be that regulation of transcription factors, cytokines and enzymes associated with NF- $\mathrm{B}$ functional activity is responsible for the mechanism of action of natural curcumins and analogs to human cells of relevance to AD (Fiala et al., 2007). In particular, $\mathrm{BDC}$ appears to be the most efficient compound in enhancing macrophage-promoted phagocytosis and $A \beta$ clearance (Fiala et al., 2007). BDC could have anti-inflammatory action related to the NF- $\kappa \mathrm{B}$ transcription pathway by promoting over-expression of MGAT3 (GnT-III) and Toll-like Receptors (TLRs), both known to be essential for normal macrophage function usually decreased in subjects with AD (Fiala et al., 2007). In fact, it was amply shown that lipopolysaccharide (LPS) binds to TLR4, and leads to the activation of NF- $\mathrm{B}$ signaling and to activation of macrophages (Taro and Akira, 2007). Moreover, the implication of NF- $\mathrm{KB}$ and TLR4 in innate immunity and its link to phagocytosis by MGAT3 was described previously (Fiala et al., 2010).

In our previous study (Gagliardi et al., 2012) synthetic curcumin derivatives and other molecules (i.e., 45 compounds) were tested in an in vitro model of $\mathrm{AD}$ (i.e., monocytic cell lines, U-937, THP-1). It was shown that BDC stimulated the Vitamin $\mathrm{D}$ receptor (VDR) gene and had immunostimulatory effects such as regulating the transcription of genes implicated in innate immunity. VDR could act by protecting neurons from $A \beta$-induced toxicity and improving phagocytosis and $A \beta$ degradation by promoting monocyte/macrophage maturation. Moreover, Liu et al. (2010) showed that curcumins may significantly suppress $B A C E 1 \mathrm{mRNA}$ in cells from AD patients and confirmed the action of curcumins on gene expression.

The aim of the present work was to evaluate the protective effects of curcuminoids in blood cells from $\mathrm{AD}$ patients. Accordingly, we investigated the effect of several curcuminoids

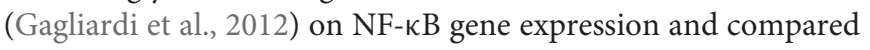
the result to the clearance of $A \beta$ in cells from $A D$ patients. Numerous papers have reported effects of curcuminoids on cellular lines and animal models (Gagliardi et al., 2012), but few reports are available about their effect on primary cells from $\mathrm{AD}$ patients. To address this, we investigated the efficacy of curcuminoids on peripheral blood mononuclear cells (PBMCs) from $\mathrm{AD}$ patients and compared the results with matched control cells. Human PBMCs appear to be a good model system to study neurodegenerative processes because they have been shown to share much of the non-synaptic biochemical environment of neurons as well as signaling pathways of the (CNS's) immune cells (Gagliardi et al., 2013; Arosio et al., 2014). In this report, based on results from in vitro cell-based studies with PBMCs, we describe the identification of a potent curcuminoid that modulates neurodegenerative signaling pathways in vitro. The results may be of relevance for future clinical studies aimed at increasing the clearance of $\mathrm{A} \beta$ and improving cognitive impairment.

\section{MATERIALS AND METHODS}

\section{AD Patients and Healthy Volunteers}

Clinical and neurological examinations of $\mathrm{AD}$ patients were conducted at the IRCCS Mondino Foundation (Pavia, Italy). Healthy volunteers were recruited to the Immunohematological and Transfusional Service and Centre of Transplantation Immunology (IRCCS Foundation "San Matteo," Pavia, Italy). Peripheral blood samples were collected from $30 \mathrm{AD}$ patients with no family history of dementia and 28 healthy volunteers over 65 years of age after obtaining written informed consent (Table 1). Before being enrolled, the subjects that participated in the study signed an informed consent form (Protocol $\mathrm{n}^{\circ} 375 / 04$ - version 07/01/2004). AD diagnosis was made according to the National Institute of Neurological and Communicative Disorders and Stroke and the AD and Related Disorders Association (NINCDS-ADRDA) criteria (Aggarwal and Harikumar, 2009). Quantification of neuropsychological

TABLE 1 | Characteristics of subjects recruited for this study.

\begin{tabular}{|c|c|c|}
\hline & AD & CTRs \\
\hline & $(n=30)$ & $(n=28)$ \\
\hline Age $(\mathrm{M} \pm \mathrm{SD})$ & $76.3 \pm 4.3$ & $75.7 \pm 7.4$ \\
\hline \multicolumn{3}{|l|}{ Sex } \\
\hline Males n (\%) & $16(53,3 \%)$ & $12(42,8 \%)$ \\
\hline Females n (\%) & 14 (46.7\%) & $16(57,2 \%)$ \\
\hline
\end{tabular}


testing, a detailed interview and clinical examinations were conducted with each subject. The severity of dementia in the AD patients was evaluated by the Mini Mental State Examination (MMSE) and carried out in accordance with The Code of Ethics of the World Medical Association (Declaration of Helsinki).

\section{PBMC Isolation and Treatment}

Peripheral blood mononuclear cells were prepared by layering peripheral blood on Ficoll-Histopaque (density $=1.077$ ) and centrifugation at $950 \times g$ for $30 \mathrm{~min}$. After isolation on a Ficoll-Histopaque layer (Sigma, Italy), cell viability was assayed by a trypan blue exclusion test and by cytometric analysis (Strober, 2001). Viable cells were used for in vitro studies with curcumins. PBMCs $\left(5 \times 10^{6}\right.$ cells with viability $\left.\geq 80 \%\right)$ were independently treated for $24 \mathrm{~h}$ with five different curcumins (0.1 $\mu \mathrm{M})$ obtained from the Human BioMolecular Research Institute in San Diego, CA, United States. The curcumins were placed in DMSO and administered to cells in media. The five curcuminoids with the greatest potency for inducing expression of genes relevant to $\mathrm{A} \beta$ phagocytosis were selected based on results from a previous report (Gagliardi et al., 2012). The chemical structures of curcumins used in the studies are shown in Figure 1. About $5 \times 10^{6}$ PBMCs were treated for $24 \mathrm{~h}$ with $0.1 \mu \mathrm{M}$ of each curcuminoid and then with $\mathrm{A} \beta 1-42(1 \mu \mathrm{M})$ (Sigma-Aldrich) for an additional $24 \mathrm{~h}$. The conditions for tests included (Figure 2): untreated, treated only with curcuminoids, treated only with $A \beta$ and, finally, treated with both curcuminoids and $\mathrm{A} \beta$.

\section{Cell Viability}

Trypan blue exclusion tests were conducted to assay cell viability after treatments. Curcuminoids and $\mathrm{A} \beta$ at $0.001-10 \mu \mathrm{M}$ were used to treat PBMCs from $\mathrm{AD}$ patients and healthy volunteers for $24 \mathrm{~h}$. The concentration range was determined based on data from similar studies carried out in different experimental models (Gagliardi et al., 2012).

\section{High-Performance Liquid Chromatography (HPLC)}

To confirm the presence/absence of intact curcuminoids in cell culture supernatants and cell pellets, an HPLC method with ultraviolet (UV) detection for the determination of the selected compounds was used. A $1000 \mu \mathrm{L}$ aliquot of cell culture supernatant was introduced onto an EMPORE Extraction Disk Cartridge (Sigma-Aldrich) under vacuum at 15 in $\mathrm{Hg}$. Cartridges were conditioned sequentially with $1000 \mu \mathrm{L}$ of methanol and $1000 \mu \mathrm{L}$ of water. Interfering substances were washed out with water $(1000 \mu \mathrm{L})$. Analytes were eluted with acetonitrile $(80 \mu \mathrm{L})$ and water $(120 \mu \mathrm{L})$. The eluate was then centrifuged at $1500 \times g$ for $5 \mathrm{~min}$ at $4^{\circ} \mathrm{C}$ and $50 \mu \mathrm{L}$ was injected onto the HPLC system. HPLC analyses were carried out using a Shimadzu LC-10Av chromatograph (Shimadzu Scientific Instrument, Inc., Columbia, MD, United States) equipped with a System Controller SCL-10Avp, an LP-10ADvp pump, an on-line Degasser DGU-14A, a SIL-10ADvp auto injector and a model CTOXX temperature controller. The system was connected to a LaChrom L-7400 variable wavelength detector (Merck, Darmstadt, Germany). Separation of selected compounds was achieved on a Chromolith Performance Column (100 mm $\times 4.6 \mathrm{~mm}$ i.d., RP-18e, Merck, Darmstadt, Germany), protected by a guard column of the same composition (5-4.6 mm i.d., RP-18e, Merck, Darmstadt, Germany). The mobile phase was prepared by adding $1 \mathrm{~mL}$ of $85 \%$ phosphoric acid to $1 \mathrm{~L}$ of a mixture of water/acetonitrile $(60: 40 \mathrm{vol} / \mathrm{vol})$ and thoroughly mixed. The column temperature was maintained at $50^{\circ} \mathrm{C}$ and the flow rate
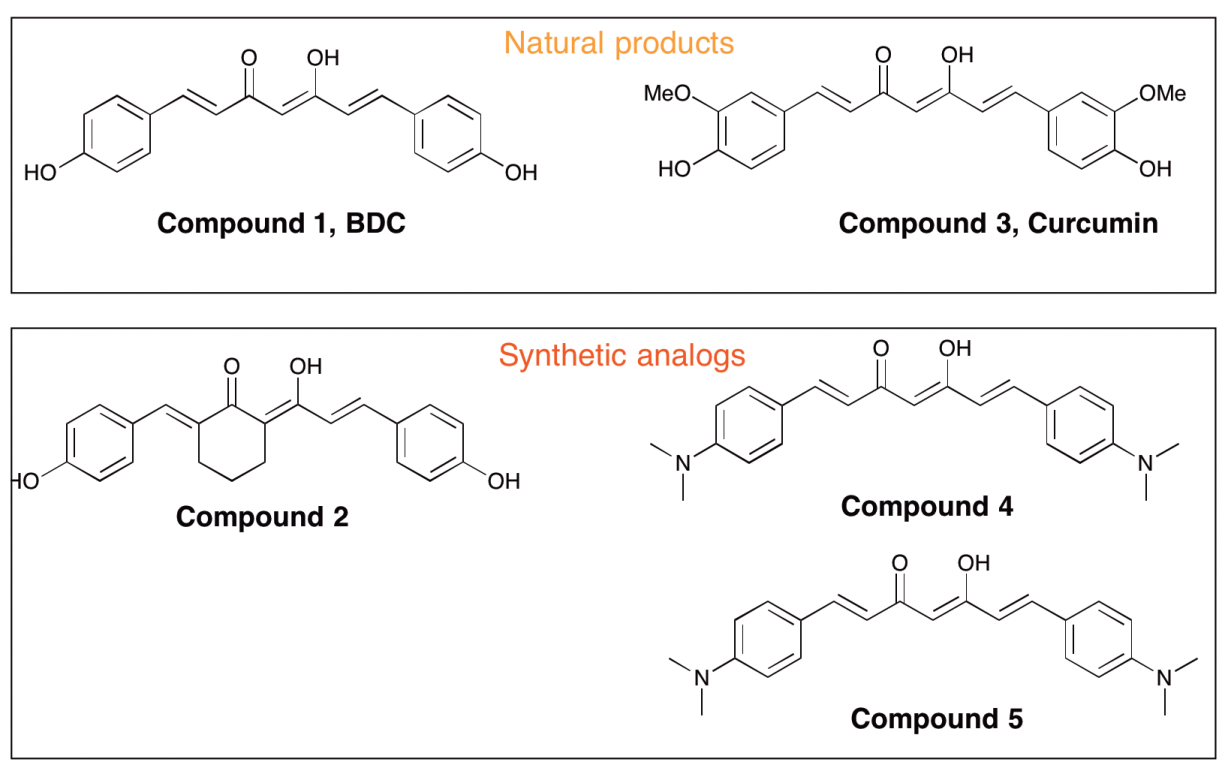

FIGURE 1 | Chemical structures of curcuminoids used for cell treatment. 


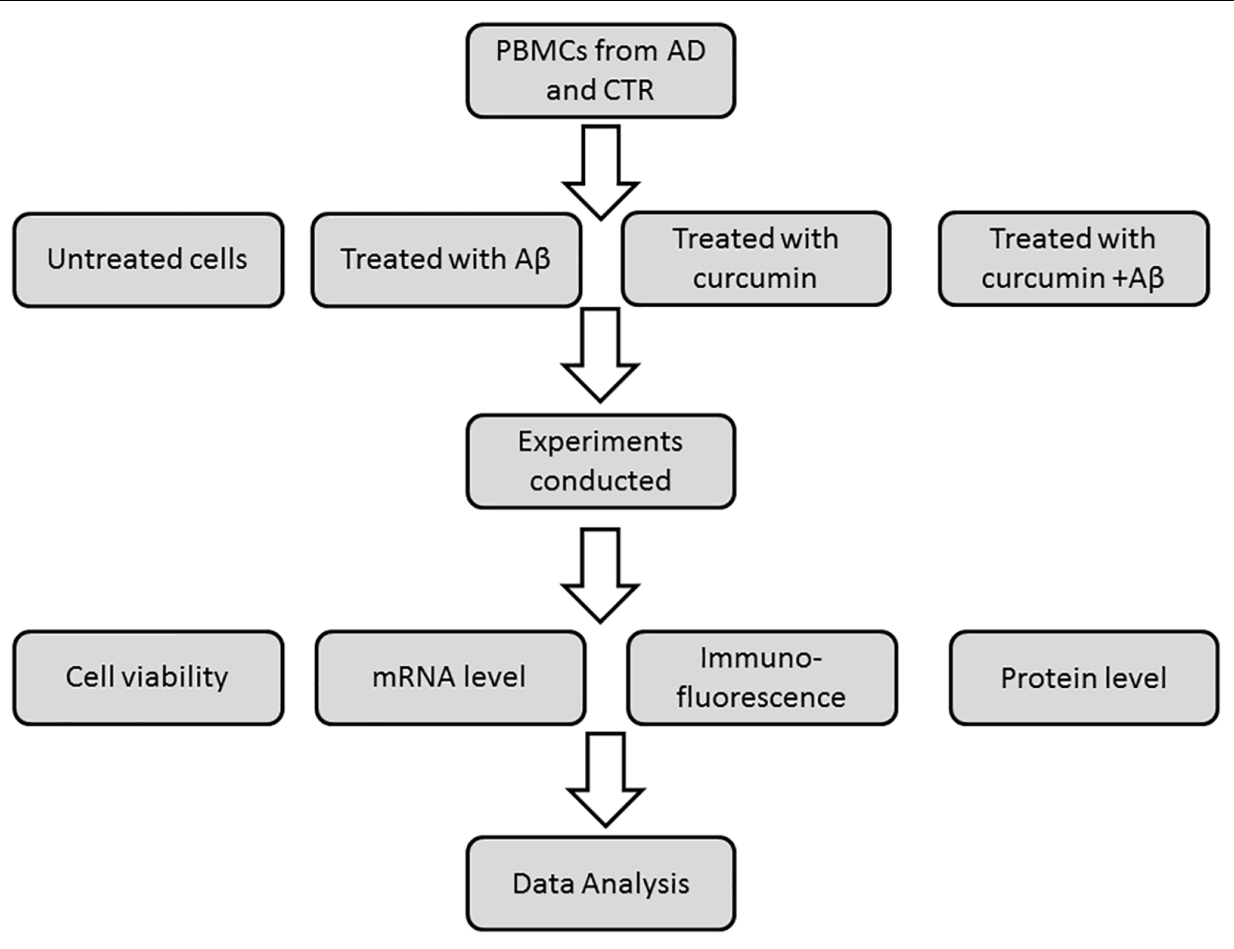

FIGURE 2 | Schematic representation of experimental plan.

was $1.5 \mathrm{~mL} / \mathrm{min}$. Curcuminoids were detected at $420 \mathrm{~nm}$. Data were acquired and analyzed using the Shimadzu LabSolution Lite software.

\section{RNA-Seq}

RNA was extracted using the Maxwell 16, Blood kit (Promega and automated purification system Maxwell 16). RNA was analyzed by a Bioanalyzer spectrophotometer to verify the quality and the concentration and stored at $-80^{\circ} \mathrm{C}$. RNA libraries were prepared by TruSeq Targeted RNA Expression NF- $\kappa$ B Panel (Illumina, United States) according to the manufacturers' instructions. The panel was integrated by BACE1 as an AD-linked gene, and VDR and MGAT3 to confirm the involvement of these two genes along the lines reported previously (Gagliardi et al., 2012). RNA processing and RNA-seq analysis was carried out using Illumina MiSeq sequencer. RNA sequencing data is available in GEO repository (GSE122438).

\section{Bioinformatics Analysis}

Differential gene expression analysis was conducted on data obtained with TruSeq Targeted RNA Expression Kit with a MiSeq sequencer. Cells from AD patients and healthy volunteers were treated with different curcuminoids, both separately and in combination and were compared to identify differentially expressed genes.

The tables of counts obtained via MiSeq reporter analysis was imported in $\mathrm{R}^{1}$ and differentially expressed genes were evaluated

${ }^{1}$ https://www.r-project.org/ using a negative binomial GLM approach (EdgeR Bioconductor). Batch effects were removed with the RemoveBatchEffects function. Differentially expressed genes had $|\log 2 \mathrm{FC}|>1$ and $p$-values $<0.1$.

To validate the expression profiles obtained by RNA-Seq, real-time PCR was conducted on MAGT3, VDR, NF- $\mathrm{B}$, and $B A C E 1$ genes selected for high or low expression levels.

\section{Immunofluorescence Microscopy}

$1 \times 10^{5}$ cells were placed on a poly-L-lysine slide (Thermo Fisher Scientific) and incubated at $37^{\circ} \mathrm{C}$ to allow cell attachment to the slide. Cells were rinsed with $1 \times$ PBS and fixed in $4 \%$ paraformaldehyde in $1 \times$ PBS. Fixed cells were washed with $1 \times$ PBS and blocked with 5\% normal goat serum in $0.1 \%$ Tween-PBS for $1 \mathrm{~h}$. Incubation with the primary mouse anti-beta amyloid antibody (1:100 dilution; Abcam) was conducted in blocking solution overnight at $4^{\circ} \mathrm{C}$. The fluorescently tagged secondary antibody CFTM 488A goat anti-rabbit (1:700 dilution; Sigma-Aldrich) was used for detection. Slides were mounted with Prolong ${ }^{\circledR}$ Gold anti-fade reagent with 4'6-diamidino-2-phenylindole (DAPI) (Invitrogen) and images were acquired by confocal microscopy (Leica DM IRBE, Leica Microsystems Srl, Italy).

\section{AlphaLISA}

Immediately after PBMCs were treated with curcumins, they were centrifuged at $16,000 \mathrm{rpm}$ for $8 \mathrm{~min}$ at room temperature and the cell pellet was incubated with lysis buffer supplemented with protease inhibitors at $4^{\circ} \mathrm{C}$ for $10 \mathrm{~min}$ and then centrifuged 
at $18,000 \times g$ for $15 \mathrm{~min}$ at $4^{\circ} \mathrm{C}$. The supernatant was used for measuring $A \beta$ 1-42. The $A \beta$ 1-42 content was determined using the AlphaLISA technique with the AlphaLISA human amyloid beta 1-42 (high specificity) kit (PerkinElmer) according to the manufacturers' instructions. In the assay, biotinylated antibody against $\mathrm{A} \beta$ 1-42 and Acceptor beads (PerkinElmer) conjugated to a 2 nd antibody against $A \beta 1-42$ was added to samples in $1 \times$ HiBlock AlphaLISA buffer on the assay plate. One antibody was specific to the $\beta$-secretase cleavage site at the $\mathrm{N}$-terminus (mouse monoclonal antibody, clone number 82E1), the second antibody
A

COMPOUND 1

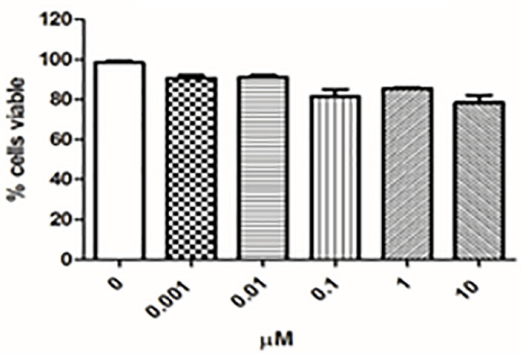

C

COMPOUND 1 + Beta Amyloid

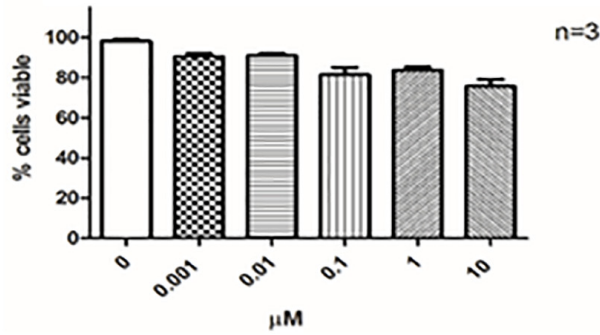

B

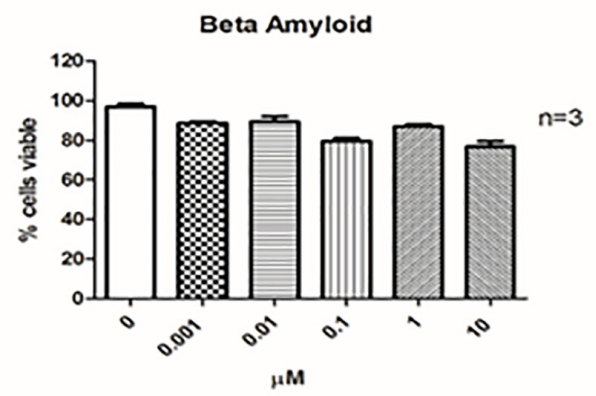

D

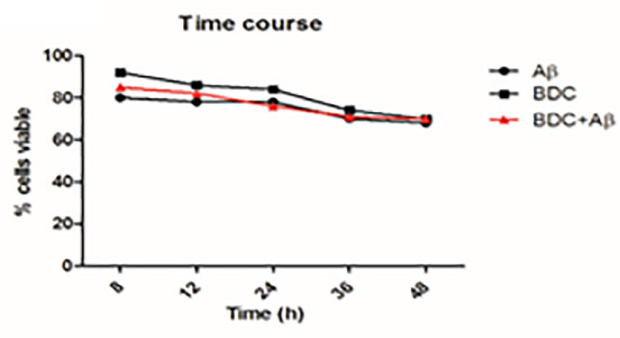

FIGURE 3 | Cell viability. Cell viability was assessed by Trypan Blue exclusion test. PBMCs (Peripheral blood mononuclear cells) were treated with COMPOUND 1 at 0.001-10 $\mu \mathrm{M}$ (A), with amyloid beta (B), with both COMPOUND 1 and amyloid beta (C), and the Time Course for all three treatments (D).

A

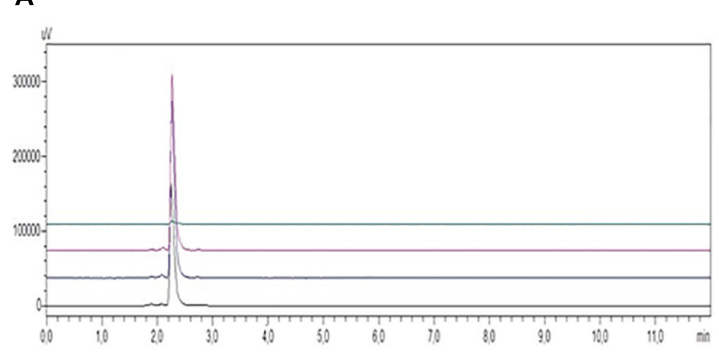

C

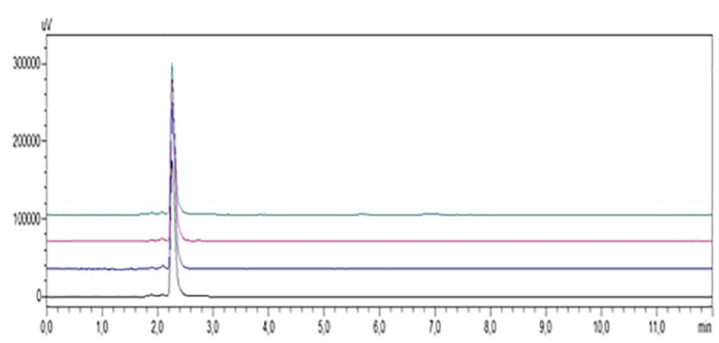

B

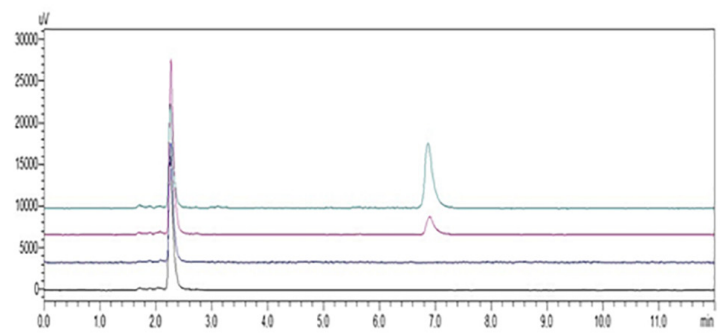

D

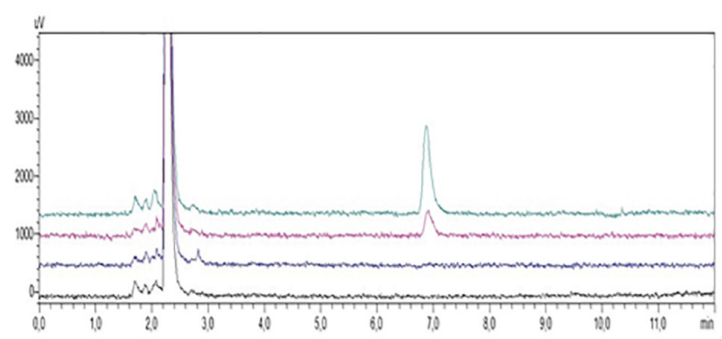

FIGURE 4 | HPLC-UV chromatograms of PBMC samples from AD patients (A, supernatants; B, pellets) and healthy controls (C, supernatants; D, pellets) incubated in the absence (black, untreated; blue, treated with $A \beta$ ) or presence (red, treated with COMPOUND 1 and A $\beta$; green, treated with COMPOUND 1). COMPOUND 1 $10 \mu \mathrm{M}$ for $24 \mathrm{~h}$ at $37^{\circ} \mathrm{C}$ in cellular pellets and supernatants. 
was specific to the C-terminus (mouse monoclonal antibody, clone number 12F4). The plate was sealed and incubated for $1 \mathrm{~h}$ at room temperature. Streptavidin-coated Donor beads were then added under subdued lighting, followed by $1 \mathrm{~h}$ incubation in the dark to bind the biotinylated antibody. When both antibodies bound $A \beta$ 1-42 fragments, they were in close enough proximity and the excitation at $680 \mathrm{~nm}$ resulted in the production of ${ }^{1} \mathrm{O}_{2}$ from the Donor beads. Energy is transferred from the singlet oxygen to the Acceptor beads, subsequently culminating in light production at $615 \mathrm{~nm}$ that was detected using an EnVision plate reader (PerkinElmer). For each group of cells, $A \beta$ 1-42 content was determined by interpolating the standard curve using $4 \mathrm{PL}$ non-linear regression. As a control the same procedure was conducted with PBMCs treated only with $A \beta$ in the absence of BDC.

\section{RESULTS}

\section{Cell Viability}

Cells treated with $10 \mu \mathrm{M}$ curcumin and $10 \mu \mathrm{M}$ A $\beta$ showed a greater decrease in viability compared with lower concentrations examined. Therefore, curcumins at $0.1 \mu \mathrm{M}$ and $\mathrm{A} \beta$ at $1 \mu \mathrm{M}$ were used for experiments (Figures 3A,B). Treatments with both molecules at the chosen concentrations did not show a significant alteration of cells viability (Figure 3C).

\section{Analysis of Curcuminoids in Supernatants and Cellular Pellets}

Although $10 \mu \mathrm{M}$ curcuminoid was the concentration with the greatest impact on cells viability, the percentage of apoptosis was considered acceptable (20\%) so it was used for HPLC analysis due to the sensitivity of the method. Under the chromatographic conditions the duration of each chromatographic run was $8 \mathrm{~min}$ and COMPOUND 1 eluted at $7 \mathrm{~min}$. HPLC analysis conducted on PBMC samples from $\mathrm{AD}$ patients and healthy volunteers treated with curcuminoids (i.e., $10 \mu \mathrm{M}$ for $24 \mathrm{~h}$ ) showed the presence of compounds in the cellular pellet. Curcumins were absent in the supernatant of cells from both $\mathrm{AD}$ patients and healthy subjects treated with curcumins (Figures 4A,C). The presence of curcuminoids in the cellular pellet was reasonable based on the lipophilicity and protein binding properties of the compounds and confirmed that they partitioned into cells (Figures 4B,D).

\section{mRNA Expression Profiles in PBMC Samples From AD Patients and Healthy Volunteers}

Compared to untreated PBMC cells of $\mathrm{AD}$ patients, mRNA expression of 12 selected genes in PBMCs from healthy controls showed a significant difference (Table 2). Among the 12 genes examined, 6 genes (i.e., NF-кB, BACE1, VDR, MGAT3, TLR7, and $T L R 8)$ were previously reported to be targets of curcumin action. Alterations of $N F-\kappa B, B A C E 1, M G A T 3$, and $V D R$ gene expression were validated with Real-Time PCR. The results confirmed the next generation sequencing (NGS) data that showed an increase
TABLE 2 | Statistically significant differentially expressed mRNAs in PBMCs from AD patients, compared to controls.

\begin{tabular}{|c|c|c|}
\hline Genes & $\log F C$ & FDR \\
\hline IFNA1 & $-5,068413935$ & 0,000490531 \\
\hline TNFSF14 & $-3,658110471$ & 0,000214144 \\
\hline IL1RN & $-3,640381192$ & 1,66533E-05 \\
\hline ICAM1 & $-3,517928503$ & $2,5152 \mathrm{E}-10$ \\
\hline RELB & $-3,095303227$ & 0,000234517 \\
\hline IRAK1 & $-3,029891347$ & 4,04098E-06 \\
\hline TRADD & $-2,854373904$ & 0,000398196 \\
\hline LTBR & $-2,307780352$ & 2,51562E-06 \\
\hline NFKB2 & $-2,264966319$ & 0,000398196 \\
\hline IRAK2 & $-2,200464564$ & 0,000137778 \\
\hline PLAU & $-2,199648435$ & 0,007553911 \\
\hline VCAM1 & $-2,155015236$ & 0,016657456 \\
\hline TICAM1 & $-1,920135409$ & 0,005236392 \\
\hline NFKBIE & $-1,719026115$ & 0,000234517 \\
\hline MMP9 & $-1,672886236$ & 0,01143092 \\
\hline TLR9 & $-1,622129773$ & 0,004608774 \\
\hline TNFRSF1A & $-1,620666312$ & 0,001389893 \\
\hline TNFAIP3 & $-1,538997066$ & 0,004768896 \\
\hline IKBKG & $-1,53268413$ & 0,003992276 \\
\hline CXCL1 & $-1,397816804$ & 0,081832301 \\
\hline TNFRSF10B & $-1,312723196$ & 0,000398196 \\
\hline GADD45B & $-1,311377024$ & 0,006364934 \\
\hline SOD2 & $-1,268237434$ & 0,005538847 \\
\hline VDR & $-1,25733448$ & 0,001665746 \\
\hline ELK1 & $-1,025052967$ & 0,016657456 \\
\hline MGAT3 & $-0,99923567$ & 0,006115305 \\
\hline XIAP & $-0,997730728$ & 0,061153047 \\
\hline EGR1 & $-0,890765445$ & 0,055696396 \\
\hline TLR6 & $-0,760645822$ & 0,04190734 \\
\hline TNFRSF1B & $-0,518149337$ & 0,081953512 \\
\hline REL & 1,079234282 & 0,077638505 \\
\hline MYC & 1,20491787 & 0,077638505 \\
\hline CD69 & 1,482195001 & 0,027318454 \\
\hline BIRC3 & 1,494054357 & 0,01156061 \\
\hline CD27 & 1,53452282 & 0,046143966 \\
\hline MALT1 & 1,882689476 & 0,022264388 \\
\hline CHUK & 2,176330259 & 0,000748631 \\
\hline BACE1 & 2,25413641 & 0,068195351 \\
\hline TLR3 & 2,995531758 & 0,000234517 \\
\hline NFKB & 3,002989135 & 0,005755391 \\
\hline
\end{tabular}

Transcripts were considered as differentially expressed when $\mid \log _{2}$ (disease sample/healthy control) $\mid \geq 1$ and a FDR $\leq 0.1$.

of $N F-\kappa B$ and $B A C E 1$ in cells from AD patients compared to cells from healthy volunteers and a decrease of MGAT3 and VDR in cells from AD patients compared to cells from healthy controls (Table 2).

\section{Treatment of PBMCs From AD and Healthy Volunteers With Curcuminoids}

Peripheral blood mononuclear cells from $\mathrm{AD}$ patients and healthy volunteers treated with curcuminoids (i.e., $0.1 \mu \mathrm{M}$, 


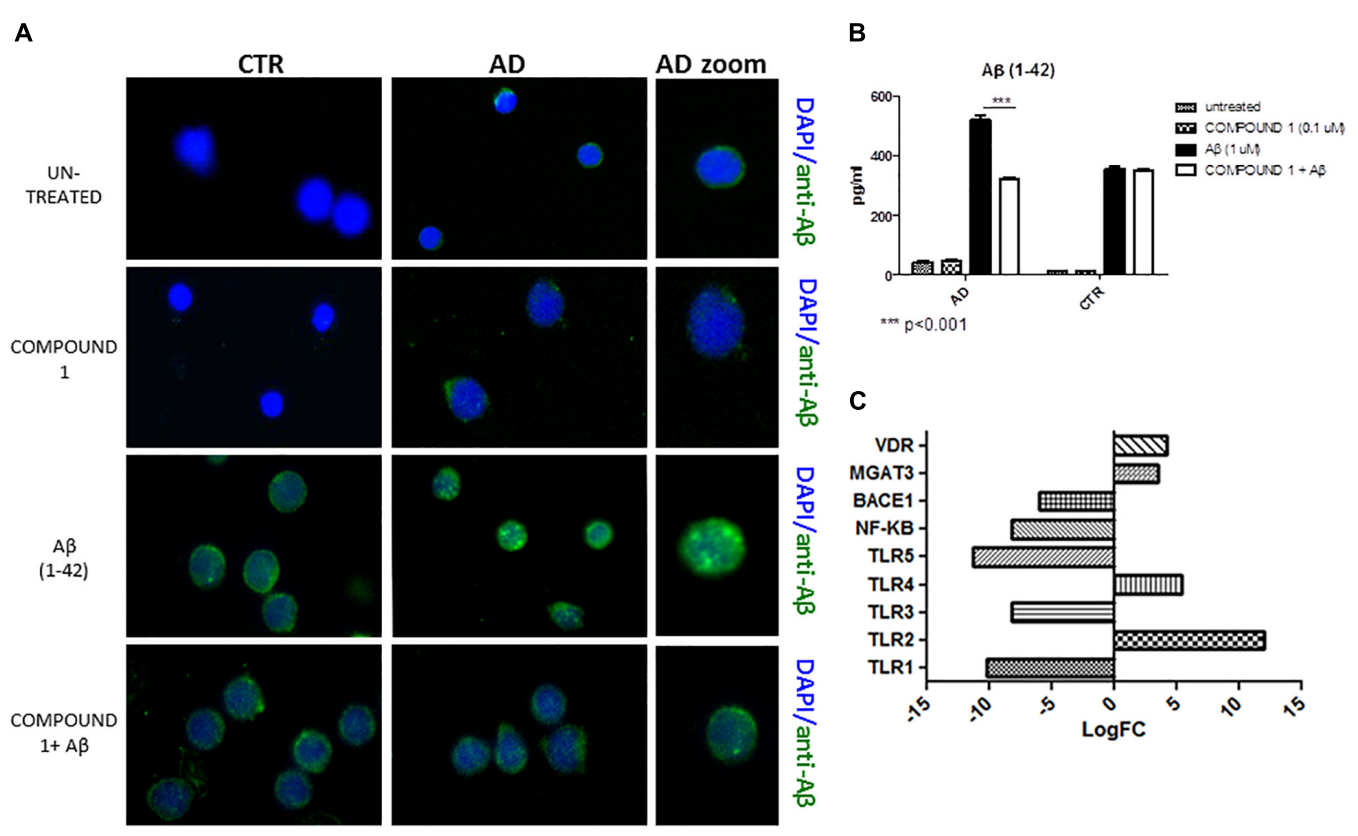

FIGURE 5 | Peripheral blood mononuclear cells from AD patients and control subjects treated with A $(48 \mathrm{~h}$ ) or untreated, COMPOUND 1 (24 h) and COMPOUND 1 $(24 \mathrm{~h})+\mathrm{A} \beta(24 \mathrm{~h})$. (A) Immunohistochemistry images; (B) A $\beta$ Alpha Technology Assays; (C) Deregulated RNAs for PBMCs treated with A $\beta$ and treated with COMPOUND $1+A \beta$.
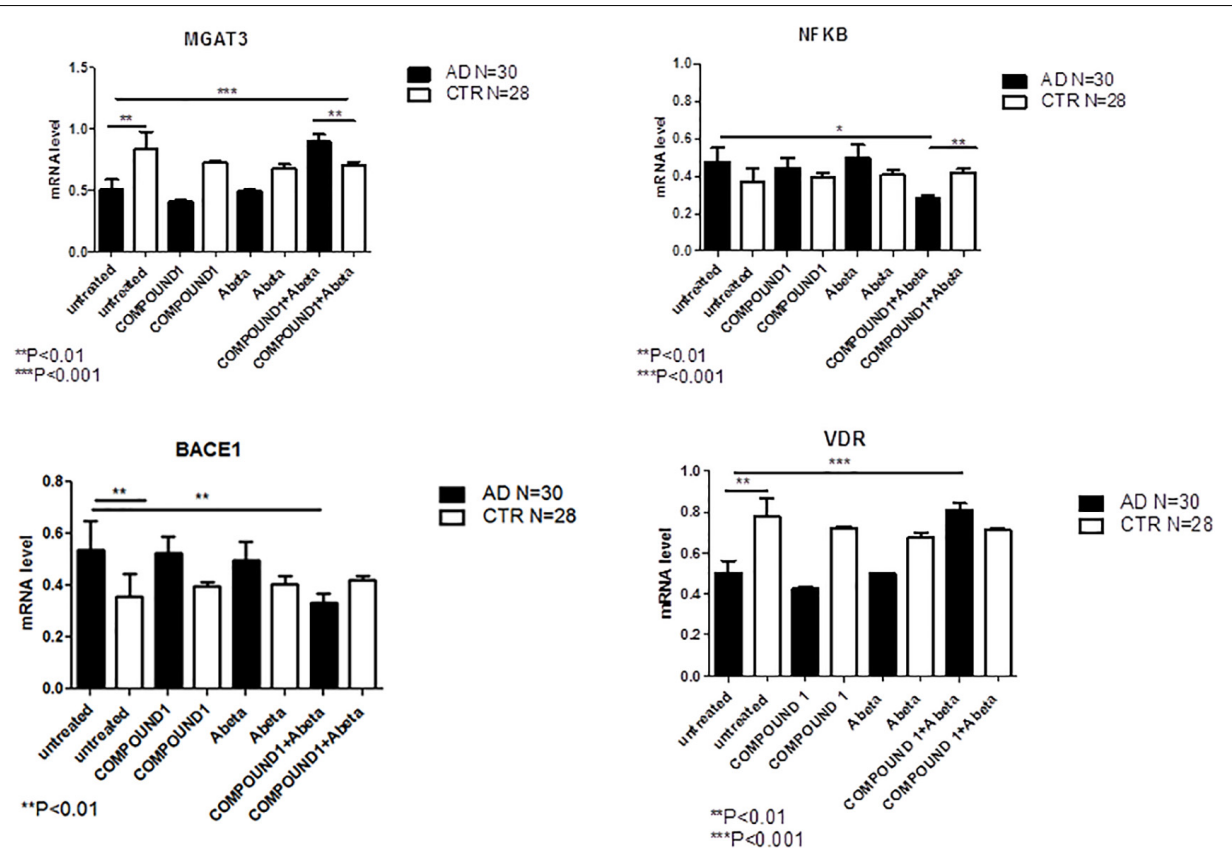

FIGURE 6 | MGAT3, NF-KB, BACE1, and VDR gene expression in PBMCs from AD patients and control subjects treated with $A \beta$ (48 h) or untreated, and COMPOUND $1(24 \mathrm{~h})$ and COMPOUND $1(24 \mathrm{~h})+\mathrm{AB}(24 \mathrm{~h})$.

$24 \mathrm{~h}$ ) showed a significant alteration in gene expression in cells from AD patients (Supplementary Table S1). Compared to cells from healthy volunteers, COMPOUND 1 was the most potent compound in regulating genes expression and caused a twofold increase after treatment in cells from $\mathrm{AD}$ patients Compared to
PBMCs from healthy controls, down-regulation of MGAT3 was observed $(\log 2 \mathrm{FC}=18)$ in untreated PBMCs of AD patients. In contrast, over-expression of MGAT3 was observed in PBMCs of $\mathrm{AD}$ patients treated with curcuminoids (i.e., 7- and 18-fold increase with COMPOUND 1 and 3, respectively). This showed 


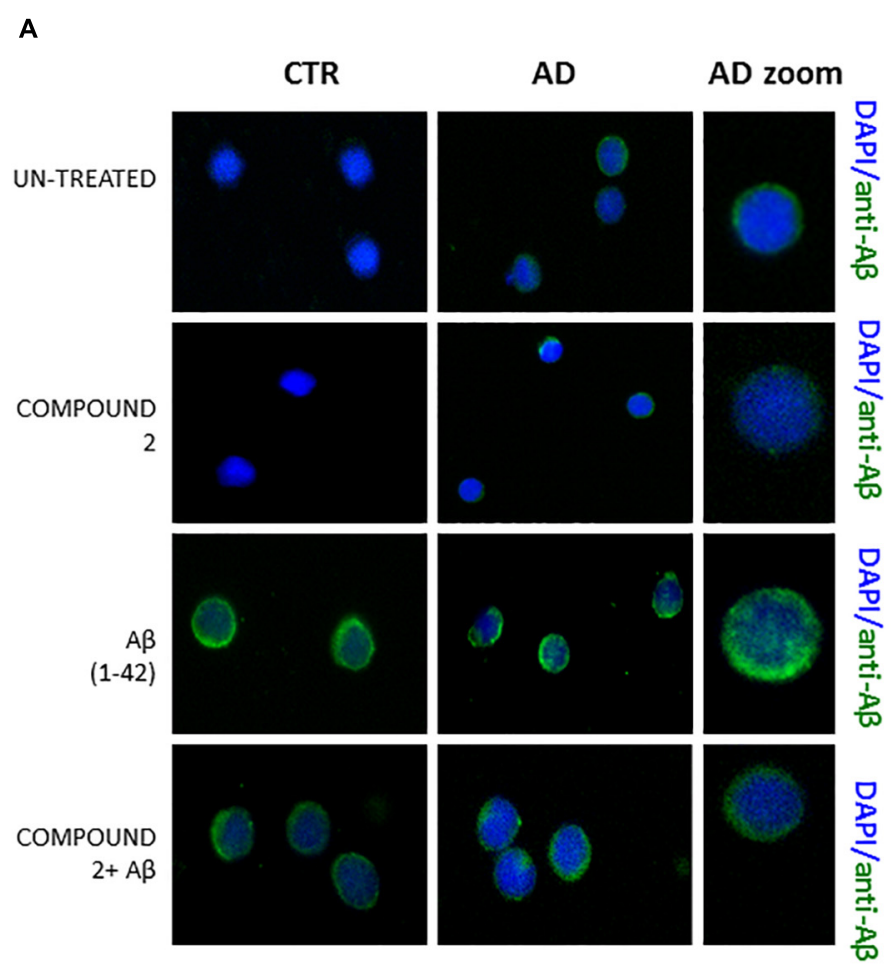

B

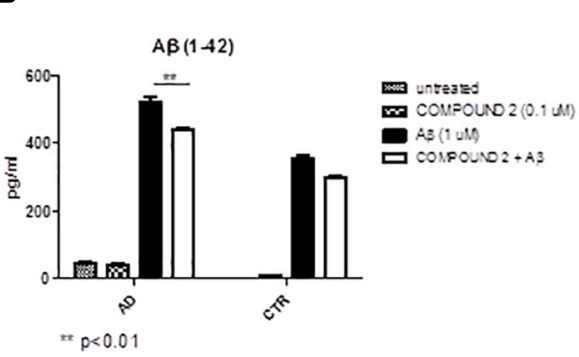

C

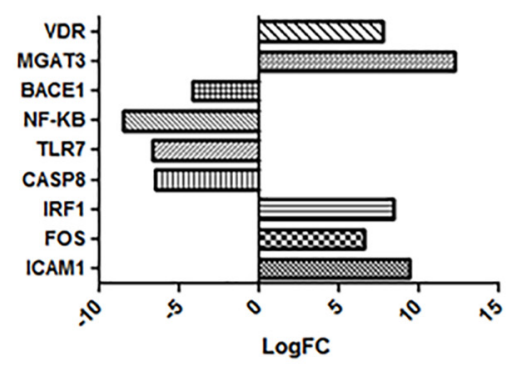

FIGURE 7 | Peripheral blood mononuclear cells from AD patients and control subjects treated with A $(48 \mathrm{~h}$ ) and untreated, COMPOUND 2 (24 h) and COMPOUND $2(24$ h) $+A \beta(24$ h). (A) Immunohistochemistry images; (B) A $\beta$ Alpha Technology Assays; (C) Deregulated RNAs between PBMCs treated with A $\beta$ and treated with COMPOUND $2+A \beta$.

that curcuminoids were able to induce transcription of MGAT3 in PBMCs from $\mathrm{AD}$ patients even in the absence of $\mathrm{A} \beta$.

\section{Treatment of PBMCs From AD and Healthy Volunteers With $A \beta$}

Treatment of PBMCs from AD patients with A $\beta$ 1-42 $(1 \mu \mathrm{M})$ caused significant alterations in genes expression but only in cells from AD patients (Supplementary Table S2). Compared to untreated PBMC cells from healthy volunteers, results showed that treatment of PBMCs from AD patients afforded a greater number of altered genes. Compared to PBMCs from healthy volunteers, 20 genes were up-regulated in PBMCs from AD patients after treatment with $\mathrm{A} \beta(0.1 \mu \mathrm{M}, 24 \mathrm{~h})$. For example, MGAT3 and VDR were increased $\log 2 \mathrm{FC}$, five and twofold, respectively. TLR4, 5, 7, and 8 were up-regulated $\log 2 \mathrm{FC}, \mathrm{X}$-, $\mathrm{X}$-, etc-fold, respectively. Compared to PBMCs from healthy volunteers, 15 genes were down-regulated in PBMCs from AD patients treated with $0.1 \mu \mathrm{M}$ for $24 \mathrm{~h}$. For example, CCR5, $C D 27$, and CD83 genes involved in inflammatory pathway were down-regulated four-, three-, and twofold $\log 2 \mathrm{FC}$, respectively.

\section{Effect of COMPOUND 1 Treatment on PBMCs From AD Patients and Healthy Volunteers}

Individual $\mathrm{PBMCs}$ from $30 \mathrm{AD}$ patients and 28 healthy volunteers were treated with COMPOUND 1 (i.e., $0.1 \mu \mathrm{M}, 24 \mathrm{~h}$ ), and then
A $\beta 1 \mu \mathrm{M}$ was added to the cell culture for the next $24 \mathrm{~h}$ and $\mathrm{A} \beta$ and gene expression was quantified.

\section{A $\beta$ Protein Quantification}

Immunofluorescence results afforded a qualitative measure of $A \beta$ in PBMCs. A decrease of green fluorescence in PBMCs from $\mathrm{AD}$ patients in the presence of COMPOUND $1(0.1 \mu \mathrm{M}, 24 \mathrm{~h})$ showed a decrease of $A \beta$ (Figure $5 \mathbf{A}$ ).

An AlphaLISA assay showed a quantitatively and statistically significant decrease $(p<0.01)$ of $\mathrm{A} \beta$ in PBMCs from AD patients treated with COMPOUND 1 (Figure 5B). In contrast, a statistically significant difference was not observed in PBMCs from healthy volunteers treated with COMPOUND $1(0.1 \mu \mathrm{M}$, $24 \mathrm{~h})$.

\section{Gene Expression}

NGS data showed that, compared to PBMCs from healthy volunteers, treatment of PBMCs from $\mathrm{AD}$ patients with COMPOUND 1 (i.e., $0.1 \mu \mathrm{M}, 24 \mathrm{~h}$ ) caused transcriptional changes in 9 genes (Figure 5C). Compared to cells from healthy volunteers TRL2 and TRL4 were up-regulated (5-and 10 -fold, respectively) after treating PBMCs from $\mathrm{AD}$ patients with COMPOUND $1(0.1 \mu \mathrm{M}, 24 \mathrm{~h})$ based on quantitative RTPCR analysis. Compared to PBMCs from healthy volunteers, treatment of PBMCs from $\mathrm{AD}$ patients with COMPOUND $1(0.1 \mu \mathrm{M}, 24 \mathrm{~h})$ showed a statistically significant increase $(p<0.01)$ of genes involved in A $\beta$ clearance (i.e., MGAT3 and 

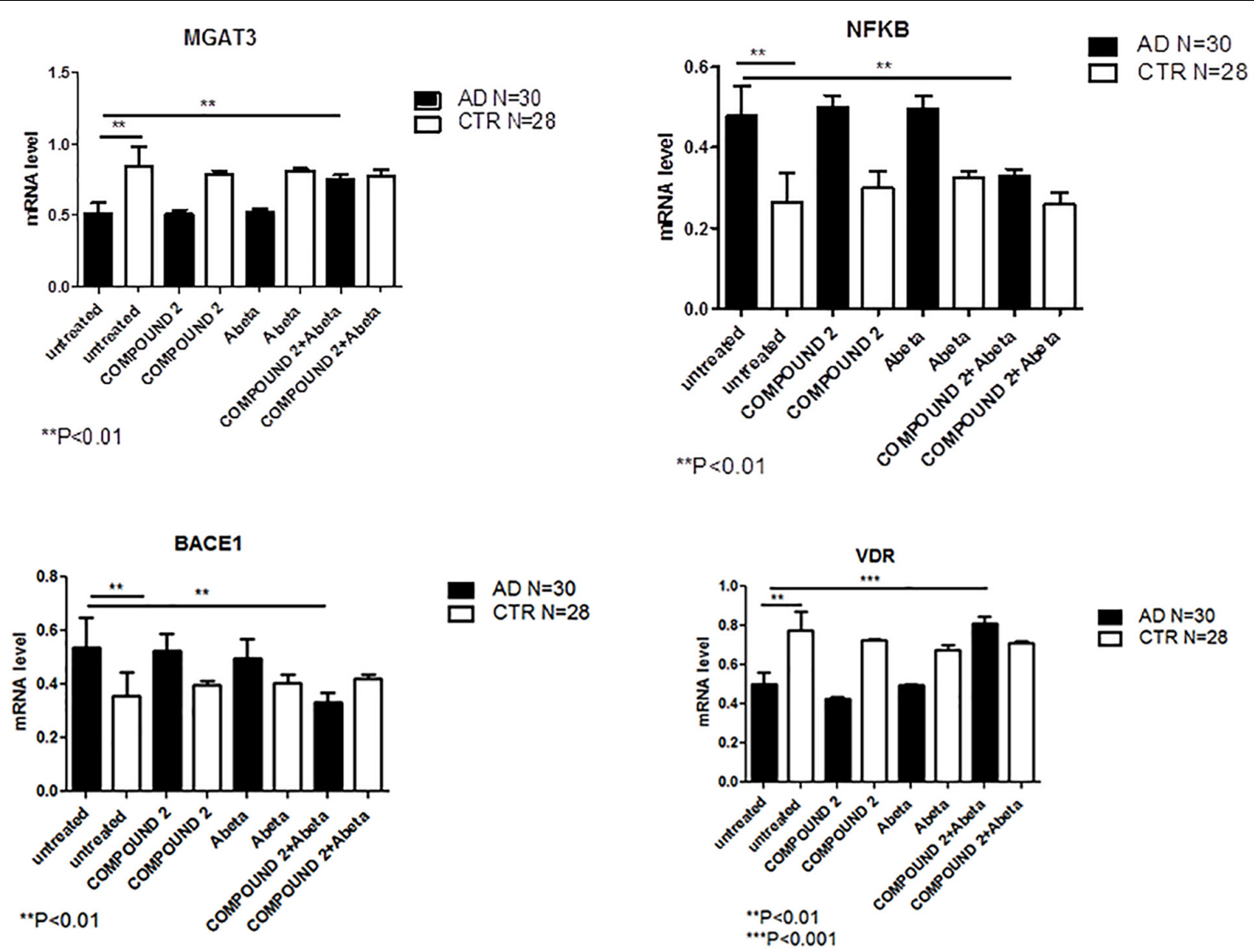

FIGURE 8 | MGAT3, NF-кB, BACE1, and VDR gene expression in PBMCs from AD patients and control subjects treated with A (48 h) or untreated, and COMPOUND 2 (24 h) or COMPOUND $2(24 \mathrm{~h})+\mathrm{A} \beta(24 \mathrm{~h})$.

$V D R$, four and fivefold increase, respectively) and a decrease in $N F-\kappa B$ and BACE1 (6- and 8-fold-decrease, respectively) (Figure 6).

\section{Effect of COMPOUND 2 Treatment on PBMCs From AD Patients and Healthy Volunteers}

Peripheral blood mononuclear cells from $30 \mathrm{AD}$ patients and 28 healthy subjects were treated with COMPOUND 2 (i.e., $0.1 \mu \mathrm{M}$ for $24 \mathrm{~h}$ ) and then $\mathrm{A} \beta$ (i.e., $1 \mu \mathrm{M}$ ) was added to the cells for the next $24 \mathrm{~h}$.

\section{A $\beta$ Protein Quantification}

Compared to healthy volunteers, qualitative results of immunofluorescence and quantitative results of AlphaLISA showed a significant decrease of $\mathrm{A} \beta(p<0.01)$ in PBMCs from $\mathrm{AD}$ patients treated with COMPOUND $2(0.1 \mu \mathrm{M}, 24 \mathrm{~h})$ (Figures 7A,B). No significant differences in $\mathrm{A} \beta$ was observed for PBMCs from healthy volunteers treated with COMPOUND 2 although there was a slight reduction in $\mathrm{A} \beta$ deposits.

\section{Gene Expression}

Compared to healthy volunteers, treatment of PBMCs from AD patients with COMPOUND 2 (i.e., $0.1 \mu \mathrm{M}$ for $24 \mathrm{~h}$ ) showed transcriptional changes in 9 genes (i.e., ICAM1, FOS, IRF1, MGAT3, VDR, TLR7, CASP8, NFKB, and BACE1, 9-, 6-, 8-, 12-, and 7-fold, increase, respectively, and 6-, 6-, 8-, and 4-fold, decrease, respectively) (Figure 7C). Data from quantitative RT-PCR were in accordance with NGS data described above and with COMPOUND 2 treatment results that showed a decrease in $N F-\kappa B$ and BACE1 and an increase of MGAT3 and VDR $(p<0.01)$ (Figure 8).

\section{Effect of COMPOUNDS 3-5 Treatment on PBMCs From AD Patients and Healthy Subjects}

Peripheral blood mononuclear cells from $30 \mathrm{AD}$ patients and 28 healthy volunteers were treated with COMPOUND 3 (i.e., $0.1 \mu \mathrm{M}$ for $24 \mathrm{~h}$ ) and then $\mathrm{A} \beta$ (i.e., $1 \mu \mathrm{M}$ ) was added to cells for the next $24 \mathrm{~h}$.

\section{$A \beta$ Protein Quantification}

Qualitative results from immunofluorescence showed a decrease in $A \beta$ similar to COMPOUNDS 1 and 2 (Figure 9A), but quantitative results from AlphaLISA were less significant $(p<0.05)$ than the results of COMPOUNDS 1 and 2 treatments (Figure 9B). No significant differences in immunofluorescence were observed in PBMCs from healthy subjects treated with 
A

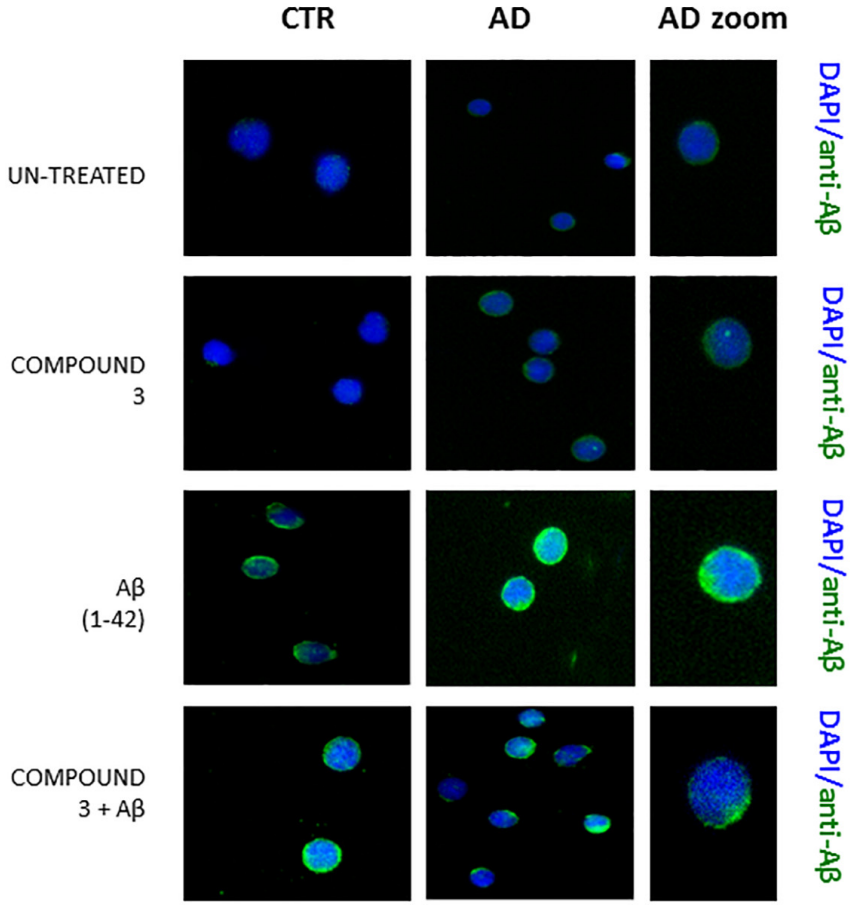

B

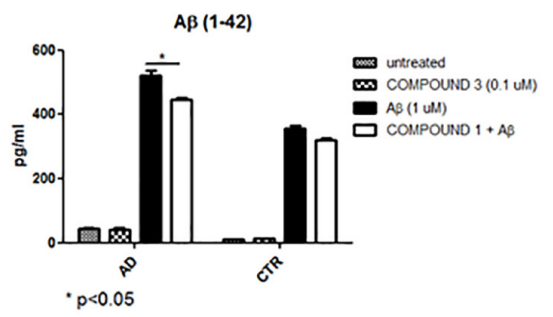

C

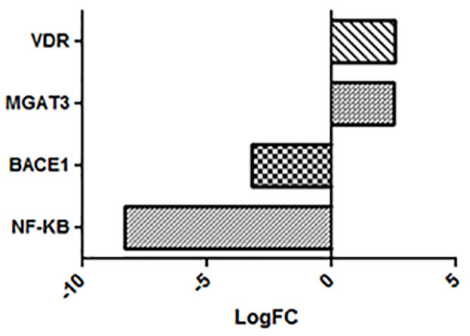

FIGURE 9 | Peripheral blood mononuclear cells from AD patients and control subjects treated with A $(48$ h) or untreated, COMPOUND 3 (24 h) or COMPOUND 3 $(24 h)+A \beta(24 h)$.

COMPOUND 4 and 5, despite evidence there was a slight decrease in $\mathrm{A} \beta$ deposits.

\section{Gene Expression}

COMPOUND 3 decreased gene expression of target genes compared to COMPOUND 1 or COMPOUND 2. NGS analysis revealed alteration in 4 genes (i.e., MGAT3, CD40, TLR8, and PTGS2) (Figure 9C). Validation of NGS results with quantitative RT-PCR confirmed a statistically significant $(p<0.01, p<0.001)$ increase of MGAT3 and VDR and a decrease of $N F-\kappa B$ and BACE1 (Figure 10).

\section{DISCUSSION}

Alzheimer's Disease is a progressive, degenerative brain disease that is the most common cause of dementia in elderly people. One of the main pathogenic factors in $\mathrm{AD}$ includes amyloid plaques derived from cleavage of amyloid precursor protein (APP) by $\mathrm{BACE} 1$ in neurons. Moreover, it has been shown that regulation of gene expression related to $\mathrm{A} \beta$ clearance is also altered in $\mathrm{AD}$ (Fiala et al., 2007; Sebollela et al., 2012).

The strength of this work is the use of human PBMCs from $\mathrm{AD}$ and age-matched control individuals to examine curcuminoid effects on $\mathrm{A} \beta$ clearance gene regulation as anti-AD compounds. We analyzed the protective effect of curcuminoids and investigated two main pathways: BACE1/NF- $\kappa \mathrm{B}$ and MGAT3/VDR. The results of the studies may be relevant to the use of curcuminoids in prevention of $\mathrm{AD}$ working via $\mathrm{A} \beta$ clearance mechanisms. In particular, we studied how curcumins act on cell susceptibility to $\mathrm{A} \beta$ accumulation. We conducted studies that showed treatment with curcumin that may decrease the predisposition of $\mathrm{A} \beta$ to accumulate into cells.

In untreated PBMCs, our data showed that, BACE1 and $N F-\kappa B$ genes were up-regulated in PBMCs from $\mathrm{AD}$ patients compared to PBMCs from healthy volunteers. Increases in both $B A C E 1$ and $N F-\kappa B$ have been reported in AD brain (Chen et al., 2012; Sebollela et al., 2012) but have not been described in peripheral cells of AD patients. Chen and collaborators showed that $N F-\kappa B$ regulates $B A C E 1$ with consequent toxic $A \beta$ generation (Chami et al., 2012). Data herein showed an increase of $A \beta$ 1-42 in PBMCs from AD patients where corresponding elevated levels of $N F-\kappa B$ and $B A C E 1$ mRNAs were present. Recently, a $N F-\kappa B$-binding element was identified in the human $B A C E 1$ promoter region (Chami et al., 2012).

$M G A T 3$ and BACE1 working together may also be involved in the $A \beta$ clearance pathway: MGAT3 may regulate the degradation of BACE1 in lysosomes (Kizuka et al., 2016). This constitutes one important step related to $\mathrm{A} \beta$-plaque formation and MGAT3 may also stabilize BACE1 in oxidative stress conditions (Hickman et al., 2008; Palmigiano et al., 2016). Compared to PBMCs from controls, MGAT3 and VDR have been reported to be downregulated in PBMCs from AD subjects (Fiala et al., 2007). In addition, compared to healthy subjects, macrophage function is decreased in subjects with AD (Hickman et al., 2008). An increase of MGAT3 functional activity may improve macrophage viability, 


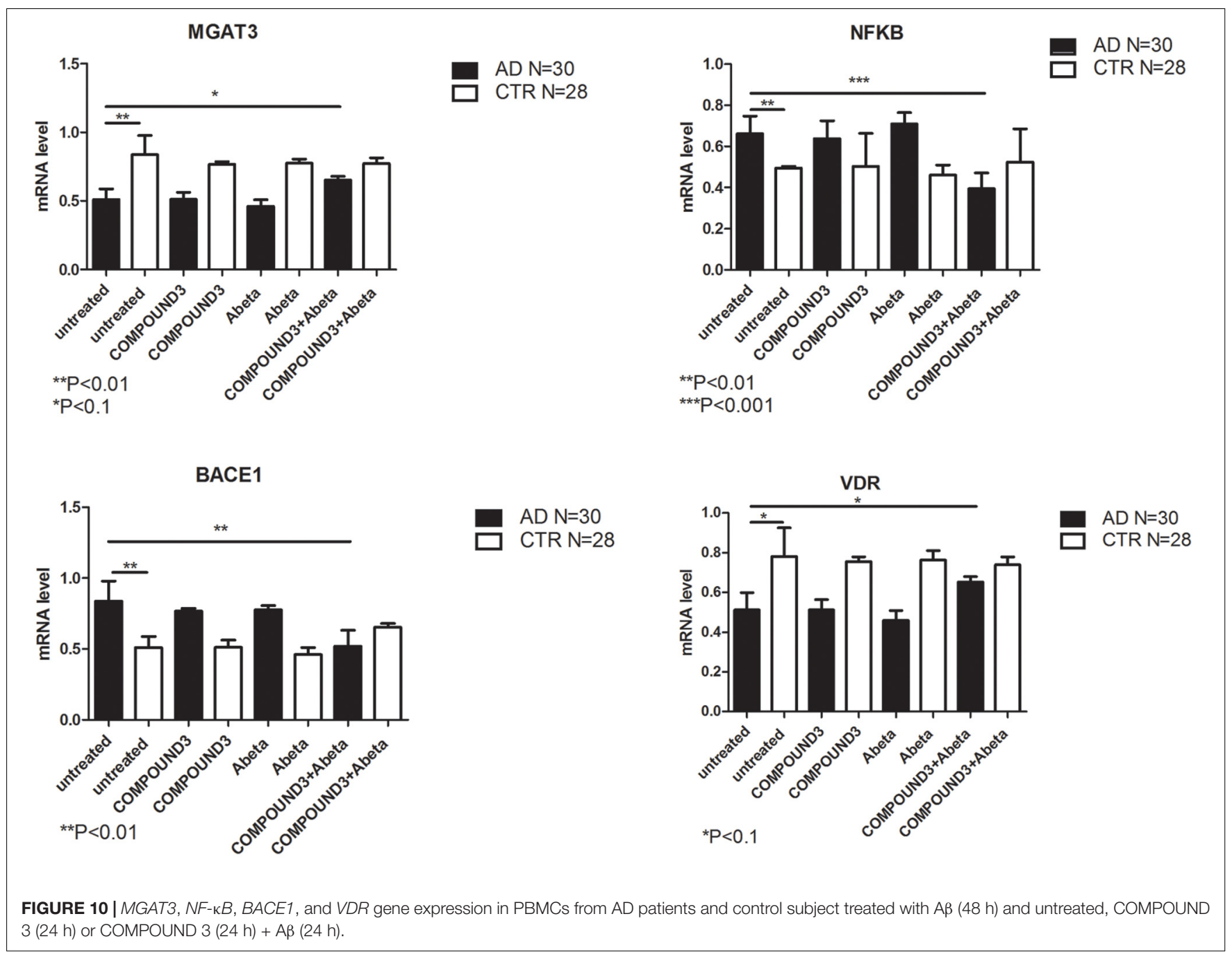

because it has been previously shown that MGAT3 silencing inhibited $\mathrm{A} \beta$ phagocytic function of control monocytes.

To support the hypothesis that curcuminoids selectively enhance A $\beta$ phagocytosis, attenuate APP maturation and alter gene transcription in PBMCs of $\mathrm{AD}$ patients we tested the effects of curcuminoids on PBMCs from patients with $\mathrm{AD}$ disease (Farmer et al., 2000; Cashman et al., 2012). In brief, our data shows curcumin treatment (i.e., particularly BDC) produced a decrease of intracellular $\mathrm{A} \beta$ aggregates, an increase of phagocytosis (e.g., the MGAT3 pathway) and a reduction of inflammation.

Results of treatment of PBMCs from $\mathrm{AD}$ patients with curcuminoids (and subsequently treated with $A \beta$ to induce $A \beta$ aggregation) showed an ability to act on cell susceptibility to $A \beta$ accumulation for three curcumin analogs (COMPOUNDS 1, 2, and 3). COMPOUND 1 appeared to be the most potent.

Data herein showed $N F-\kappa B$ and $B A C E 1$ were decreased after pre- with curcuminoids. Because $N F-\kappa B$ signaling leads to an up-regulation of $B A C E 1$ gene expression and facilitates APP processing in $\mathrm{PBMCs}$ from $\mathrm{AD}$ patients, its decline following treatment would decrease the formation of $A \beta$ fragments by
BACE1. In addition, the decrease in $N F-\kappa B$ leads to suppression of the inflammatory cascade, one of the major pathways in AD. PBMCs from AD patients treated with curcumin led to an increase in gene expression of MGAT3, VDR, and TLR4 similar to controls. Normal elevated levels of MGAT3 have been associated with an effective degradation and disposal process of $A \beta$, although the detailed mechanism has not yet been fully elucidated (Kizuka et al., 2015).

Vitamin D3, VDR's endogenous ligand, regulates transcription of genes of innate immunity (Lin, 2016). It has been hypothesized that Vitamin D3 possesses immunostimulant effects and also induces phagocytosis and degradation of $\mathrm{A} \beta$ by monocytes/macrophages maturation (Aggarwal and Harikumar, 2009; Masoumi et al., 2009). We suggest that increased MGAT3 and VDR inhibit A $\beta$ accumulation and decreases inflammation. Moreover, in most systems, vitamin

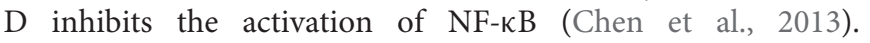
VDR stimulation induced by curcuminoids could shift this balance to and increase inhibitory activity of VDR on NFкB (Geldmeyer-Hilt et al., 2011). For both MGAT3 and VDR pathways, an increase of TLR4 may also play a role in NF- $\mathrm{B}$ 
repression and on macrophage activation even if it still remains unclear what acts as a TLR4 activator.

Future work will be to identify and characterize molecular factors of the inflammatory process and the relationships between them. Our data support continued pharmacological studies. In the future, curcumins may be established as important dietary supplements in asymptomatic AD subjects (Reddy et al., 2018). Finally, BDC may be useful in subjects that have more propensities to develop $\mathrm{AD}$ or in subjects that are in the early stages of $A \beta$ accumulation but that is still not damaging to prevent the degeneration to $\mathrm{A} \beta$ plaques, a key event in $\mathrm{AD}$ pathogenesis.

\section{CONCLUSION}

The data presented herein may contribute to the understanding of the etiopathogenetic mechanism of AD. Further studies may be warranted to investigate a possible preventive approach in human subjects that may be susceptible to develop $\mathrm{AD}$ but that still do not have clinical signs. In a cell model, we have shown that Treatment with curcuminoids inhibits the pathological mechanisms that are responsible for some

\section{REFERENCES}

Aggarwal, B. B., and Harikumar, K. B. (2009). Potential therapeutic effects of curcumin, the anti-inflammatory agent, against neurodegenerative, cardiovascular, pulmonary, metabolic, autoimmune and neoplastic diseases. Int. J. Biochem. Cell Biol. 41, 40-59. doi: 10.1016/j.biocel.2008. 06.010

Ahmed, T., Enam, S. A., and Gilani, A. H. (2010). Curcuminoids enhance memory in an amyloid-infused rat model of Alzheimer's disease. Neuroscience 169, 1296-1306. doi: 10.1016/j.neuroscience.2010.05.078

Anderson, A. M., Mitchell, M. S., and Mohan, R. S. (2000). Isolation of curcumin from turmeric. J. Chem. Educ. 77, 359. doi: 10.1021/ed07 7 p359

Arosio, B., D’Addario, C., Gussago, C., Casati, M., Tedone, E., Ferri, E., et al. (2014). Peripheral blood mononuclear cells as a laboratory to study dementia in the elderly. Biomed. Res. Int. 2014:169203. doi: 10.1155/2014/ 169203

Blennow, K., de Leon, M. J., and Zetterberg, H. (2006). Alzheimer's disease. Lancet 368, 387-403.

Cashman, J. R., Gagliardi, S., Lanier, M., Ghirmai, S., Abel, K. J., and Fiala, M. (2012). Curcumins promote monocytic gene expression related to beta-amyloid and superoxide dismutase clearance. Neurodegener. Dis. 10, 274-276. doi: 10. $1159 / 000333123$

Chami, L., Buggia-Prévot, V., Duplan, E., Del Prete, D., Chami, M., Peyron, J. F., et al. (2012). Nuclear factor- $\kappa$ B regulates $\beta$ APP and $\beta$ and $\gamma$-secretases differently at physiological and supraphysiological $A \beta$ concentrations. J. Biol. Chem. 13, 24573-24584. doi: 10.1074/jbc.M111.33 3054

Chen, C. H., Zhou, W., Liu, S., Deng, Y., Cai, F., Tone, M., et al. (2012). Increased NF-kappaB signalling up-regulates BACE1 expression and its therapeutic potential in Alzheimer's disease. Int. J. Neuropsychopharmacol. 15, 77-90. doi: 10.1017/S1461145711000149

Chen, Y., Zhang, J., Ge, X., Du, J., Deb, D. K., and Li, Y. C. (2013). Vitamin D receptor inhibits nuclear factor kappaB activation by interacting with IkappaB kinase beta protein. J. Biol. Chem. 288, 19450-19458. doi: 10.1074/jbc.M113. 467670

Farmer, P. K., He, X., Schmitz, M. L., Rubin, J., and Nanes, M. S. (2000). Inhibitory effect of NF-kappaB on 1,25-dihydroxyvitamin $\mathrm{D}(3)$ and retinoid X receptor function. Am. J. Physiol. Endocrinol. Metab. 279, E213-E220.
$\mathrm{AD}$ pathways such as the activation of inflammation and of accumulation of $\mathrm{A} \beta$.

\section{AUTHOR CONTRIBUTIONS}

SG, VF, and CP ran the experiments and wrote the manuscript. SS ran the experiments. SZ performed the bioinformatic analysis. PR performed the HPLC analysis. SB recruited the healthy subjects. $\mathrm{AC}$ and $\mathrm{ES}$ recruited the patients. OP and $\mathrm{CC}$ revised the paper. JC provided the curcumins and revised the paper.

\section{FUNDING}

This work was funded by Italian Ministry of Health (RC13-16).

\section{SUPPLEMENTARY MATERIAL}

The Supplementary Material for this article can be found online at: https://www.frontiersin.org/articles/10.3389/fphar. 2018.01404/full\#supplementary-material

Fiala, M., Liu, P. T., Espinosa-Jeffrey, A., Rosenthal, M. J., Bernard, G., Ringman, J. M., et al. (2007). Innate immunity and transcription of MGATIII and Toll-like receptors in Alzheimer's disease patients are improved by bisdemethoxycurcumin. Proc. Natl. Acad. Sci. U.S.A. 104, 12849-12854.

Gagliardi, S., Abel, K., Bianchi, M., Milani, P., Bernuzzi, S., Corato, M., et al. (2013). Regulation of FMO and PON detoxication systems in ALS human tissues. Neurotox. Res. 23, 370-377. doi: 10.1007/s12640-012-9356-1

Gagliardi, S., Ghirmai, S., Abel, K. J., Lanier, M., Gardai, S. J., Lee, C., et al. (2012). Evaluation in vitro of synthetic curcumins as agents promoting monocytic gene expression related to beta-amyloid clearance. Chem. Res. Toxicol. 25, 101-112. doi: $10.1021 /$ tx200246t

Geldmeyer-Hilt, K., Heine, G., Hartmann, B., Baumgrass, R., Radbruch, A., and Worm, M. (2011). 1,25-dihydroxyvitamin D3 impairs NF-kappaB activation in human naive B cells. Biochem. Biophys. Res. Commun. 407, 699-702. doi: 10.1016/j.bbrc.2011.03.078

Hickman, S. E., Allison, E. K., and El Khoury, J. (2008). Microglial dysfunction and defective beta-amyloid clearance pathways in aging Alzheimer's disease mice. J. Neurosci. 28, 8354-8360. doi: 10.1523/JNEUROSCI.0616-08.2008

Kizuka, Y., Kitazume, S., Fujinawa, R., Saito, T., Iwata, N., Saido, T. C., et al. (2015). An aberrant sugar modification of BACE1 blocks its lysosomal targeting in Alzheimer's disease. EMBO Mol. Med. 7, 175-189. doi: 10.15252/emmm. 201404438

Kizuka, Y., Nakano, M., Kitazume, S., Saito, T., Saido, T. C., and Taniguchi, N. (2016). Bisecting GlcNAc modification stabilizes BACE1 protein under oxidative stress conditions. Biochem. J. 1, 21-30. doi: 10.1042/BJ20150607

Kumar, A., Singh, A., and Ekavali. (2015). A review on Alzheimer's disease pathophysiology and its management: an update. Pharmacol. Rep. 67, 195-203. doi: 10.1016/j.pharep.2014.09.004

Lin, R. (2016). Crosstalk between Vitamin D Metabolism, VDR Signalling, and Innate Immunity. BioMed Res. Int. 2016:1375858. doi: 10.1155/2016/1375858

Liu, H., Li, Z., Qiu, D., Gu, Q., Lei, Q., and Mao, L. (2010). The inhibitory effects of different curcuminoids on beta-amyloid protein, beta-amyloid precursor protein and beta-site amyloid precursor protein cleaving enzyme 1 in swAPP HEK293 cells. Neurosci. Lett. 485, 83-88. doi: 10.1016/j.neulet.2010.08.035

Masoumi, A., Goldenson, B., Ghirmai, S., Avagyan, H., Zaghi, J., Abel, K., et al. (2009). 1alpha,25-dihydroxyvitamin D3 interacts with curcuminoids to stimulate amyloid-beta clearance by macrophages of Alzheimer's disease patients. J. Alzheimers Dis. 17, 703-717. doi: 10.3233/JAD-20091080 
McKhann, G., Drachman, D., Folstein, M., Katzman, R., Price, D., and Stadlan, E. M. (1984). Clinical diagnosis of Alzheimer's disease: report of the NINCDSADRDA Work Group under the auspices of Department of Health and Human Services Task Force on Alzheimer's Disease. Neurology 34, 939-944.

Palmigiano, A., Barone, R., Sturiale, L., Sanfilippo, C., Bua, R. O., Romeo, D. A., et al. (2016). CSF N-glycoproteomics for early diagnosis in Alzheimer's disease. J. Proteomics 131, 29-37. doi: 10.1016/j.jprot.2015.10.006

Panza, F., Seripa, D., Solfrizzi, V., Imbimbo, B. P., Lozupone, M., Leo, A., et al. (2016). Emerging drugs to reduce abnormal beta-amyloid protein in Alzheimer's disease patients. Expert Opin. Emerg. Drugs 21, 377-391.

Reddy, P. H., Manczak, M., Yin, X., Grady, M. C., Mitchell, A., Tonk, S., et al. (2018). Protective effects of Indian spice curcumin against amyloid- in Alzheimer's disease. J. Alzheimers Dis. 61, 843-866. doi: 10.3233/JAD- 170512

Sebollela, A., Freitas-Correa, L., Oliveira, F. F., Paula-Lima, A. C., Saraiva, L. M., Martins, S. M., et al. (2012). Amyloid-beta oligomers induce differential gene expression in adult human brain slices. J. Biol. Chem. 287, 7436-7445. doi: $10.1074 /$ jbc.M111.298471

Selkoe, D. J. (2001). Alzheimer's disease: genes, proteins, and therapy. Physiol. Rev. $81,741-766$.

Strober, W. (2001). Trypan blue exclusion test of cell viability. Curr. Protoc. Immunol. 21, A.3B.1-A.3B.2.
Taro, K., and Akira, S. (2007). Signaling to NF-кB by Toll-like receptors. Trends Mol. Med. 13, 460-469.

Zhang, L., Fiala, M., Cashman, J., Sayre, J., Espinosa, A., Mahanian, M., et al. (2006). Curcuminoids enhance amyloid-beta uptake by macrophages of Alzheimer's disease patients. J. Alzheimers Dis. 10, 1-7.

Conflict of Interest Statement: The authors declare that the research was conducted in the absence of any commercial or financial relationships that could be construed as a potential conflict of interest.

The reviewer AA and handling Editor declared their shared affiliation at the time of review.

Copyright (e) 2018 Gagliardi, Franco, Sorrentino, Zucca, Pandini, Rota, Bernuzzi, Costa, Sinforiani, Pansarasa, Cashman and Cereda. This is an open-access article distributed under the terms of the Creative Commons Attribution License (CC BY). The use, distribution or reproduction in other forums is permitted, provided the original author(s) and the copyright owner(s) are credited and that the original publication in this journal is cited, in accordance with accepted academic practice. No use, distribution or reproduction is permitted which does not comply with these terms. 